\title{
Environmental risk factors for Cryptosporidium infection in an island from Western Venezuela
}

\author{
Leonor Chacín-Bonilla/ ${ }^{+}$, Fernando Barrios' ${ }^{1}$ Yulaicy Sanchez \\ Postgrado de Inmunología, Instituto de Investigaciones Clínicas, Facultad de Medicina, Universidad del Zulia, Apartado Postal 23, Mara- \\ caibo, Venezuela ${ }^{1}$ Departamento de Microbiología, Facultad de Odontología, Universidad del Zulia, Maracaibo, Venezuela
}

Few investigations have been conducted on risk factors for Cryptosporidium infection in communities from developing countries. A study was conducted to determine the prevalence and risk factors for cryptosporidiosis in San Carlos island, Venezuela. A sample of 515 subjects (mean age $\pm S D: 21.4 \pm 17.8$ years) was surveyed. Single fecal specimens were collected and modified Ziehl-Neelsen carbolfuchsin staining of formalin-ether concentrate stools were examined for identification of the parasite. Infections with Cryptosporidium (67 of 515, 13\%) were common. Prevalence of the parasite varied among sectors of the community; 34 of 67(50.7\%) cases of cryptosporidiosis clustered in two sectors with extreme poverty. Variables strongly associated with a higher risk for the infection $(p<0.01)$ were residing in these sectors versus the remainder, living in a hut or small residence versus a brick or larger house, using an area of backyard rather than a toilet or latrine for defecation, and having contact with soil contaminated with human feces. Crowding was also a risk ( $p<0.05)$. Contact with human feces contaminated-soil may be an important mode of transmission and poverty a predisposing factor for the infection.

Key words: Cryptosporidium - cryptosporidiosis - epidemiology- transmission-risk factors - Venezuela

The prevalence of cryptosporidiosis in humans is higher in endemic areas and predominates in young children (Reinthaler 1989, Ungar 1990, Enriquez et al. 1997, Agnew et al. 1998, Clark 1999, Nuñez et al. 2003, Fayer 2004). Recent data from 16 case-control studies from 1994 to 2003 indicate that the average overall prevalence of infection in immunocompetent patients in developing countries is $12.7 \%$ in those with diarrhea and $4.5 \%$ carry the parasite asymptomatically (Bushen et al. 2006).

The risk factors for outbreak transmission of cryptosporidiosis are well known. In industrialized countries, waterborne outbreaks by contaminated drinking or recreational water are increasingly frequent (Fayer 2004). However, cases associated with epidemics represent only less than $10 \%$ of all diagnosed cases (Nichols 2003). Risk factors for sporadic acquisition of the infection may be relative to the setting. Based on several case-control studies from USA, United Kingdom, and Australia, the main risk factors for human cryptosporidiosis are contact with others cases, foreign travel, and contact with cattle; contact with pets is either not significant or negatively associated with risk (Hunter \& Thompson 2005). Until now, only one epidemiological study has done independent analysis of risk factors for Cryptosporidium hominis and Cryptosporidium parvum. The former was associated with travel abroad and contact with children's nappies, and the latter was only linked to contact with cattle (Hunter et al. 2004).

Financial support: Alcaldía del Municipio Insular Padilla (grant 0301), Isla de Toas, Estado Zulia, Venezuela

+ Corresponding autor: leonorbonilla42@yahoo.com

Received 26 June 2007

Accepted 25 January 2008
In developing countries, the environmental risk factors and routes of transmission for infection are not well defined. Despite the numerous surveillance studies reported, few investigations have been conducted on the source of this parasite in a community where infection is endemic (Chen et al. 1992, Newman et al. 1993, Molbak et al. 1994, Bern et al. 2002, Redlinger et al. 2002). There is a case-control study from Guinea-Bissau in which keeping pigs or dogs and storage of cooked food for later consumption were associated to infection (Molbak et al. 1994). Contamination of water supplies and infection of domestic animals in a Brazilian slum (Newman et al. 1993), lacking adequate municipal water and sewage services in three Mexican settings (Redlinger et al. 2002), and using a field rather that a toilet or latrine for defecation in a Peruvian community (Bern et al. 2002) were correlated with a higher risk of cryptosporidiosis.

In Venezuela, it is known that Cryptosporidium infection is common (Perez-Schael et al. 1985, Chacín-Bonilla et al. 1992, 1997). However, geographic distribution and epidemiologic features of infection in the country are mostly unknown since studies among population-based community are very scarce. Infection rates from $0.6 \%$ to $9.9 \%$ have been reported from three poor settings (Chacín-Bonilla et al. 1993, 2000, Devera et al. 2005) but studies on risk factors and modes of transmission of infection are lacking. The aim of the present report was to assess the prevalence and environmental risk factors for cryptosporidiosis in San Carlos island, Venezuela.

\section{PATIENTS, MATERIALS AND METHODS}

Area and population studied - San Carlos (SC) island is located in the state of Zulia, Western Venezuela, at latitude $11^{\circ} 00^{\prime} \mathrm{N}$, between longitudes $71^{\circ} 30^{\prime}$ and $72^{\circ} 00^{\prime} \mathrm{W}$. The climate is tropical with daily temperatures ranging from 23 to $29^{\circ} \mathrm{C}$ and annual rainfall from 500 to 
$1000 \mathrm{~mm}$. The area is divided into six sectors: the urban center named El Pueblo (EP); four periurban settlements, El Caño (EC), Fuego Vivo (FV), Pueblo Nuevo (PN), and San Bernardo (SB); and the rural sector named El Manglar (EM). Most of the households in SB and PN are huts, with zinc, wooden, or rushed walls and roofs, and earthern floors. Residences from the remainder sectors are usually brick constructed with roofs of asbestos.

The island features low socioeconomic status and poor environmental sanitation. Adequate water supply, sewerage, and waste disposal are lacking. Drinking water is supplied by lighter, stored in public tanks, and distributed to households with indoor plumbing. Garbage is burned or thrown away on nearby bushes and can be found deposited in several places. The economy is based upon subsistence fishing. The population consisted of 1339 inhabitants distributed in 280 households at the time of sampling according to the local authorities. A sample of $536(40 \%)$ residents from 84 randomly chosen households from all sectors of the area was selected for the study.

Field procedures and stool examination - A crosssectional stool survey was conducted during the rainy season. The field workers visited each home. The householders were asked to respond to a questionnaire about socioeconomic indicators and potential risk factors for Cryptosporidium, such as type of housing and employment, water source and storage, consumption of uncooked produce, number of residents, sanitary facilities, ownership of animals, soil contact, places where children play. Each individual of the household responded to questions about demographic data, occupation, environmental exposures that could represent risk factors for the parasite, and current or previous two-month diarrheal illness. Feeding modes of infants were recorded.

Fresh single fecal specimens were collected and transported to the health center of SC. The consistency of each specimen was recorded, a portion of each sample was preserved in $10 \%$ formalin, and a portion was fixed in polyvinyl alcohol and transported to our laboratory. For identification of Cryptosporidium, modified ZiehlNeelsen carbolfuchsin staining (García et al. 1983) was used to examine concentrates of stools fixed in formalin. Each stained smear was microscopically examined at 1000X magnification using an oil-immersion lens, for at least $15 \mathrm{~min}$ before it was considered negative. For other parasites, iron-hematoxylin-stained smears (Tompkins \& Miller 1947) of polyvinyl alcohol fixed specimens and formalin-ether concentrates (Ritchie 1948) were examined.

Statistical analysis - Chi-square and Fisher's exact tests were used for comparison of proportions, and analysis of variance for comparison of means. The associations between the presence of the infection and age categories, presence of diarrhea, or potential risk factors were assessed by calculating odds ratios and their $95 \%$ confidence intervals. Multiple logistic regression was used to test for the simultaneous involvement of several factors that might influence the risk of infection. A value of $p<0.05$ was considered significant.
Ethical considerations - The ethical aspects of the study were approved by the Academic Committee of the Postgrado of Inmunología, Facultad de Medicina, Universidad del Zulia. Individual consent was obtained during the households survey before enrollment in the study.

\section{RESULTS}

Of the 536 subjects who agreed with the study, 515 (96\%) participated in the investigation; 256 (49.7\%) were males and $259(50.3 \%)$ were females. The mean age \pm SD of the participants was $21.4 \pm 17.8$ (range, 1 month to 86 years). No statistical difference among mean ages of the residents by sector was found. Infection with Cryptosporidium was common (67 of 515, 13\%) and prevalence varied by age (Table I). The parasite peaked at $\leq 5$ years of age $(\mathrm{p}<0.01)$, was predominant in children, and decreased sharply in adults $(60 / 248,24.2 \%$ versus $7 / 267,2.6 \% ; \mathrm{p}<0.001)$. Most of the subjects positive for Cryptosporidium (56 of 67, 83.6\%) were symptomless at the time of sampling or during the preceding two months. The highest prevalence of diarrhea was recorded in the youngest children, with a trend toward lower prevalence with age $(\mathrm{p}<0.001)$; diarrhea was not observed in adults. Of 515 participants, $292(56.7 \%)$ harbored one or more pathogens; Trichuris trichiura (220, 42.7\%), Ascaris lumbricoides $(210,40.8 \%)$, and Giardia lamblia (132, $25.6 \%$ ) were highly endemic. Of the 67 patients with cryptosporidiosis, mixed infections with one or more other parasitic pathogens were present in 54 (80.6\%). Of 11 children with Cryptosporidium and diarrhea, seven (63.6\%) had additional pathogens: three had G. lamblia, three had T. trichiura and two had A. lumbricoides. There were no differences in rates of diarrheal symptoms among children with or without pathogens other than Cryptosporidium (data not included).

Surveys of households showed a low socioeconomic status, i.e. frequent huts $(24 / 84,28.6 \%)$ and small residences of 1-3 rooms $(37 / 84,44 \%)$; crowded living, more than 2 sleepers per bedroom $(62 / 84,73.8 \%)$; poor sanitary conditions, $33.3 \%(28 / 84)$ of the houses lacked safe drinking water and sanitary facilities. Domestic animals, such as dogs, cats, pigs and chickens or any other fowl were present in 54/84 (64.3\%) households. SB and PN featured extreme poverty: the proportions of huts and small residences $(p<0.01)$, the houses without sanitary

\section{TABLE I}

Distribution of Cryptosporidium infections and association with diarrhea, by age, in 515 subjects from San Carlos island, Venezuela

\begin{tabular}{lcrrrrrr}
\hline & & \multicolumn{2}{c}{ Infections } & & \multicolumn{2}{c}{ With diarrhea } \\
\cline { 3 - 4 } \cline { 7 - 8 } Age (years) & n tested & $\mathrm{n}$ & $\%$ & & $\mathrm{n}$ & $\%$ \\
\hline$<1$ & 17 & 7 & 41.2 & & 3 & 42.9 \\
$1-5$ & 89 & 31 & 34.8 & & 7 & 22.6 \\
$6-15$ & 142 & 22 & 15.5 & & 1 & 4.5 \\
$16-25$ & 119 & 5 & 4.2 & & 0 & 0 \\
$\geq 26$ & 148 & 2 & 1.4 & & 0 & 0 \\
\hline Total & 515 & 67 & 13.0 & & 11 & 16.4 \\
\hline
\end{tabular}


facilities, with certain area of the backyard for defecation $(\mathrm{p}<0.01)$, indiscriminate defecation in many places of household $(p<0.05)$ and the houses that used water from dug wells $(p<0.05)$ were significantly higher than the other sectors that had better living conditions. Among sectors, there were not differences in relation to crowding and presence of animals (data not shown).

Among sectors, the prevalence of Cryptosporidium ranged from $2.9 \%$ to $29 \%$ (Table II). Residents from SB and PN had significantly higher prevalences of Cryptosporidium $(\mathrm{p}<0.001)$. The parasite also clustered by household; the 67 cases of cryptosporidiosis resided in 30 households. Factors significantly associated with the infection are showed in Table III. Since the pattern of Cryptosporidium infection was similar in SB and PN, the data were combined and compared with the remainder sectors. Variables strongly associated with a higher risk for the infection $(p<0.01)$ were residing in SB and PN versus other areas, living in a hut or a small residence

\section{TABLE II}

Distribution of Cryptosporidium infections by sector in San Carlos island, Venezuela

\begin{tabular}{lrrrr}
\hline & \multicolumn{2}{c}{ People } & & \multicolumn{2}{c}{ Infected people } \\
\cline { 5 - 5 } Sector & n tested & Mean age $\pm \mathrm{SD}$ & $\mathrm{n}(\%)$ & Mean age $\pm \mathrm{SD}$ \\
\hline El Pueblo & 101 & $24.4 \pm 18.6$ & $3(2.9)$ & $15.9 \pm 13.4$ \\
El Caño & 141 & $21.5 \pm 16.3$ & $15(10.6)$ & $6.1 \pm 4.2$ \\
Fuego Vivo & 104 & $19.5 \pm 17.4$ & $9(8.7)$ & $3.8 \pm 5.1$ \\
San Bernardo & 62 & $24.6 \pm 19.2$ & $18(29.0)$ & $6.3 \pm 4.2$ \\
Pueblo Nuevo & 67 & $19.6 \pm 16.4$ & $16(23.9)$ & $4.1 \pm 3.3$ \\
El Manglar & 40 & $21.5 \pm 19.1$ & $6(15.0)$ & $11.0 \pm 12.3$ \\
\hline Total & 515 & $21.4 \pm 17.8$ & $67(13.0)$ & $6.2 \pm 6.3$ \\
\hline
\end{tabular}

versus a brick house or a larger house, using an area of backyard rather than a toilet or latrine for defecation, and having contact with soil contaminated with human feces. Crowding ( $>2$ sleepers per bedroom) was also a risk for infection $(p<0.05)$. After data was adjusted for age, multivariable backward logistic regression analysis revealed that all these associations remained significant. Infections with $T$. trichiura and $A$. lumbricoides also significantly correlated $(\mathrm{p}<0.01)$ with all of these variables (data not shown). The risk for cryptosporidiosis did not differ by household water supply or storage, eating uncooked foods or feeding modes of infants, and having domestic animals.

\section{DISCUSSION}

Although underestimation of the prevalence of Cryptosporidium may result from the present data since single stool specimens were examined, it is likely that enhanced sensitivity can be obtained by detection of more lowintensity infections through the examination of concentrated specimens and the spending of enough time in examining each stool sample. Despite this limitation, it is unlikely that our findings reflect a bias in isolation rates for different participant groups and sectors of the area since the same laboratory tests were used for all of them. Other limitations were the lack of molecular analysis for species identification and evaluation of the level of environmental contamination with Cryptosporidium oocysts. Our investigation also had several strengths. It is one of the very few community-based studies of the epidemiology of the parasite in endemic areas (Chen et al. 1992, Newman et al. 1993, Molbak et al. 1994, Bern et al. 2002, Redlinger et al. 2002), and the first detailed description of the epidemiology of Cryptosporidium on a community-wide basis in Venezuela; the households of the partici-

TABLE III

Variables significantly associated with Cryptosporidium infection in 515 subjects from San Carlos island, Venezuela

\begin{tabular}{|c|c|c|c|c|c|c|c|}
\hline \multirow[b]{2}{*}{ Variable } & \multicolumn{2}{|c|}{$\begin{array}{l}\text { Infections } \\
n=67\end{array}$} & \multicolumn{2}{|c|}{$\begin{array}{c}\text { No infections } \\
n=448 \\
\end{array}$} & \multirow[b]{2}{*}{ OR } & \multirow[b]{2}{*}{$95 \% \mathrm{CI}$} & \multirow[b]{2}{*}{$\mathrm{p}$} \\
\hline & $\mathrm{n}$ & $\%$ & $\mathrm{n}$ & $\%$ & & & \\
\hline \multicolumn{8}{|c|}{ Place of residence } \\
\hline $\mathrm{SB}$ and $\mathrm{PN}$ & 34 & 50.7 & 95 & 21.2 & 1.74 & $1.69,1.81$ & \\
\hline Other sectors & 33 & 49.3 & 353 & 78.8 & 1.92 & $1.89,1.94$ & $<0.001$ \\
\hline \multicolumn{8}{|l|}{ Household type } \\
\hline Concrete house & 24 & 35.8 & 326 & 72.8 & 0.49 & $0.35,0.68$ & \\
\hline Hut & 43 & 64.2 & 122 & 27.2 & 2.35 & $1.86,2.97$ & $<0.01$ \\
\hline \multicolumn{8}{|c|}{ Sleepers per bedroom } \\
\hline$\leq 2$ & 2 & 2.9 & 83 & 18.5 & 0.53 & $0.41,0.64$ & \\
\hline$>2$ & 65 & 97.0 & 365 & 81.5 & 1.19 & $1.12,1.26$ & $<0.05$ \\
\hline \multicolumn{8}{|l|}{ Sanitary facility } \\
\hline Toilet or latrine & 22 & 32.8 & 328 & 73.2 & 0.44 & $0.31,0.63$ & \\
\hline None & 45 & 67.2 & 120 & 26.8 & 2.50 & $1.99,3.14$ & $<0.01$ \\
\hline \multicolumn{8}{|c|}{ Contact with feces soil-contaminated } \\
\hline Yes & 37 & 55.2 & 92 & 20.5 & 2.68 & $2.02,3.56$ & \\
\hline No & 30 & 44.8 & 356 & 79.5 & 0.56 & $0.43,0.73$ & $<0.01$ \\
\hline
\end{tabular}

CI: confidence interval; OR: odds ratio; Places of residence: SB: San Bernardo; PN: Pueblo Nuevo. 
pants were randomly selected; individuals were chosen regardless of their symptom status; the participation rate of those selected for the study was very high $(515 / 536$, $96 \%)$ which represented $38.5 \%(515 / 1339)$ of the overall population; this report provides important insights into the epidemiology of cryptosporidiosis.

Our findings revealed that Cryptosporidium infection was common in the island (13\%). However, this prevalence might shift since the infection may be seasonal (Meinhardt et al. 1996). The infection rate was higher than those observed in other communities from Venezuela (Chacín-Bonilla et al. 1993, 2000, Devera et al. 2005), Brazil (Weikel et al. 1985), and Haití (López et al. 2003). As previously noted, cryptosporidiosis predominated in the $\leq 5$ years old children $(p<0.01)$, the presence of diarrheal illness decreased significantly with age $(p<0.01)$ and the proportion of asymptomatic cysts passers was remarkable (83.6\%). These results confirm that, in endemic areas, most infected subjects are often symptomless (Mathan et al. 1985, Hojlyng et al. 1986, Janoff et al. 1990, Chacín-Bonilla et al. 1993, 2000, Esteban et al. 1998), and younger children tend to suffer the highest rates of infections and the most illness (Reinthaler 1989, Current \& García 1991, Enriquez et al. 1997, Agnew et al. 1998, Bern et al. 2002, Nuñez et al. 2003) and suggest that immunity to the parasite occurs in this area.

The most striking finding from this investigation is the strong association of Cryptosporidium with environments conducive to human fecal contamination $(p<0.001)$. Although the level of environmental contamination with Cryptosporidium oocysts was not determined, this result suggests that contact with contaminated soil in the backyards or around homes without sanitary facilities was an important source of infection in this area $(\mathrm{p}<0.01)$. The strong association between contact with feces contaminated-earth and the prevalence of A. lumbricoides and T. trichuris $(\mathrm{p}<0.01)$ indicates that soil is an important source of intestinal parasites in this area. The association of Cryptosporidium with the absence of toilet or latrine in a Peruvian community (Bern et al. 2002 ) is consistent with our results. One of the most interesting aspects of spread of the parasite in the island was the presence of specific foci of transmission in SB and PN where half of the infections clustered (Table III); the magnitude and similarity of the infection in these two sectors were notable (Table II). Clustering of positive residents within households was apparent as would be expected since transmission of the organism had been unevenly distributed in the population. SB and PN were representative of extreme poverty and are a logical focus for transmission in endemic areas. Their hygienic and sanitary conditions aided in maximizing the exposure to infection. Besides, both sectors are close to the coastal shore where moisture of the soil favours the oocysts viability. Thus, a persistent focus of oocysts near human residences and where children play is likely to increase the rate of spread in these areas. As expected, crowding was associated with a higher risk of cryptosporidiosis $(\mathrm{p}<0.05)$, suggesting that direct fecal-oral transmission is also a route of spread of Cryptosporidium in the area. It appears to be that the most important source of infection in this setting was the environment with the contamination being maximized in areas where more individuals were infected, with the person to person factor playing a less significant role.

Association of cryptosporidiosis with variables related to foods and water could not be established. Although the use of water from dug wells was a proxy for the surrounding environment or the socioeconomic status of people who used it, using water from wells rather than public tanks was not a risk factor. This result might be attributed to the fact that most $(84.3 \%, 434 / 515)$ of the inhabitants of SC used water from public tanks, resulting in small expected frequencies for those that used water from wells. Our results are consistent with the lack of correlation between infection and water supply in a shantytown from Perú (Bern et al. 2002). However, the finding contrasts with the association of infection with contamination of water supply in Brazil (Newman et al. 1993), lacking adequate municipal water in Mexican settings (Redlinger et al. 2002) and eating stored foods in Guinea Bissau (Molbak et al. 1994).

None of the factors indicative of zoonotic exposure were associated with the infection, despite large proportion of people documenting animal exposure. This result may be explained by the fact that the animals most frequently associated with zoonotic infections (calves, goats, and sheeps) were absent or rare in this area; there were not calves and only two families in the rural sector had goats and sheep. Our finding is consistent with the lack of association of infection with animals in a study from Perú (Bern et al. 2002) but contrasts with studies from Brazil (Newman et al. 1993) and Guinea Bissau (Molbak et al. 1994) that suggest domestic animals as a source of infection.

Although this study has limitations, the present results add new insights on the epidemiology of Cryptosporidium. This investigation demonstrates that contact with human feces contaminated-soil may be an important mode of transmission for infection in endemic areas. The results indicate higher prevalence rates related to poverty and low standards of hygiene and show that cryptosporidiosis, as other communicable infections, affects families living in substandard housing developments. The spread of the infection in the island and its focality in SB and PN indicate that patterns of transmission can be different in areas that are located close to each other.

In conclusion, cryptosporidiosis is a health problem in $\mathrm{SC}$ island related to extreme poverty, poor environmental sanitation, and crowding which facilitate fecal-oral transmission. This study is the first evidence for human feces contaminated-soil as an important risk and poverty as a predisposing factor for infection. Although these results can not be generalized, they clearly indicate that living conditions should be improved to avoid such widespread of the infection.

\section{ACKNOWLEDGEMENTS}

To the staff of the health center of San Carlos island for their assistance in this study. 


\section{REFERENCES}

Agnew DG, Lima AAM, Newman RD, Wuhib T, Moore RD, Guerrant RL, Sears CL 1998. Cryptosporidiosis in Northeastern Brazilian children: Association with increased diarrhea morbility. $J$ Infect Dis 177: 754-760.

Bern C, Ortega Y, Checkley W, Roberts JM, Lescano AG, Cabrera L, Verastegui M, Black RE, Sterling C, Gilman RH 2002. Epidemiologic differences between cyclosporiasis and cryptosporidiosis in Peruvian children. Emerg Infect Dis 8: 581-585.

Bushen OY, Lima AA, Guerrant RL 2006. Cryptosporidiosis. In RL Guerrant, DH Walter, PF Weller (eds), Tropical Infectious Diseases: principles, pathogens, \& practice, 2nd ed., Elsevier/ Churchill Livingstone, Philadelphia, USA, p. 1003-1014.

Chacín-Bonilla L, Bonilla MC, Soto-Torres L, Ríos Cándida I, Sardiña M, Enmanuels C, Parra AM, Sánchez-Chávez Y 1997. Cryptosporidium parvum in children with diarrhea in Zulia State, Venezuela. Am J Trop Med Hyg 56: 365-369.

Chacín-Bonilla L, De Young M, Cano G, Guanipa N, Estevez J, Bonilla E 1993. Cryptosporidium infections in a suburban community in Maracaibo, Venezuela. Am J Trop Med Hyg 49: 63-67.

Chacín-Bonilla L, Guanipa N, Cano G, Raleigh X, Quijada L 1992. Cryptosporidiosis among patients with Acquired Immunodeficiency Síndrome in Zulia State, Venezuela. Am J Trop Med Hyg 47: $582-586$

Chacín-Bonilla L, Sánchez-Chávez Y 2000. Intestinal parasitic infections, with a special emphasis on cryptosporidiosis, in Amerindians from Western Venezuela. Am J Trop Med Hyg 62: 347-352.

Chen YG, Yao FB, Li HS, Shi WS, Dai MX, Lu M 1992. Cryptosporidium infection and diarrhea in rural and urban areas of Jiangsu, People's Republic of China. J Clin Microbiol 30: 492-494.

Clark DP 1999. New insights into human cryptosporidiosis. Clin Microbiol Rev 12: 554-563.

Current WL, García LS 1991. Cryptosporidiosis. Clin Microbiol Rev 4: 325-358.

Devera R, Blanco Y, Cabello E 2005. Elevada prevalencia de Cyclospora cayetanensis en indígenas del estado Bolivar, Venezuela. Cad Saude Pública 21: 1778-1784.

Enriquez FJ, Avila CR, Santos JI, Tanaka-Kido J, Vallejo O, Sterling CR 1997. Cryptosporidium infections in mexican children: clinical, nutritional, enteropathogenic, and diagnostic evaluations. Am J Trop Med Hyg 56: 254-257.

Esteban JG, Aguirre C, Flores A, Strauss W, Angles R, Mas-Coma S 1998. High Cryptosporidium prevalences in healthy Aymara children from the Northern Bolivian Altiplano. Am J Trop Med Hyg 58: 50-55.

Fayer R 2004. Cryptosporidium: a water-borne zoonotic parasite. Vet Parasitol 126: 37-56.

García LS, Bruckner DA, Brewer TC, Shimizu RY 1983. Techniques for recovery and identification of Cryptosporidium oocysts from stool specimens. J Clin Microbiol 18: 185-190.

Hojlyng N, Molbak K, Jepsen S 1986. Cryptosporidium spp., a frequent cause of diarrhea in Liberian children. J Clin Microbiol 23: $1109-1113$
Hunter PR, Hughes S, Woodhouse S, Syed Q, Verlander NQ, Chalmers RM, Morgan K, Nichols G, Beeching N, Osborn K 2004. Sporadic cryptosporidiosis case-control study with genotyping. Emerg Infect Dis 10: 1241-1249.

Hunter PR, Thompson RCA 2005. The zoonotic transmission of Giardia and Cryptosporidium. Int J Parasitol 35: 1181-1190.

Janoff EN, Mead PS, Mead JR, Echeverría P, Bodhidatta L, Bhaibulaya M, Sterling CR, Taylor DN 1990. Endemic Cryptosporidium and Giardia lamblia infections in a Thai orphanage. Am J Trop Med Hyg 43: 248-256.

López AS, Bendik JM, Alliance JY, Roberts JM, da Silva AJ, Moura IN, Arrowood MJ, Eberhard ML, Herwaldt BL 2003. Epidemiology of Cyclospora cayetanensis and other intestinal parasites in a community in Haiti. J Clin Microbiol 41: 2047-2054.

Mathan MM, Venkatesan S, George R, Mathew M, Mathan VI 1985. Cryptosporidium and diarrhea in Southern Indian children. Lancet 2: 1172-1175.

Meinhardt PL, Casemore DP, Miller KB 1996. Epidemiologic aspects of human cryptospodiriosis and the role of waterborne transmission. Epidemiol Rev 18: 118-136.

Molbak K, Aaby P, Hojlyng N, da Silva AP 1994. Risk factors for Cryptosporidium diarrhea in early childhood: a case-control study from Guinea-Bissau, West Africa. Am J Epidemiol 139: 734-740.

Newman RD, Wuhib T, Lima AM, Guerrant RL, Sears CL 1993. Environmental sources of Cryptosporidium in an urban slum in Northeastern Brazil. Am J Trop Med Hyg 49: 270-275.

Nichols G 2003. Using existing surveillance data. In PR Hunter, M Waite, E Ronchi (eds), Drinking Water and Infectious Disease: Establishing the Links, CRC Press, Boca Raton, USA, p. 131-141.

Nuñez FA, González OM, González I, Escobedo AA, Cordoví RA 2003. Intestinal coccidia in Cuban pediatric patients with diarrhea. Mem Inst Oswaldo Cruz 98: 539-542.

Perez-Schael I, Boher Y, Mata L, Perez M, Tapia FJ 1985. Cryptosporidosis in Venezuelan children with acute diarrhea. Am J Trop Med Hyg 34: 721-722.

Redlinger T, Corella-Barud V, Graham J, Galindo A, Avitia R, Cárdenas V 2002. Hyperendemic Cryptosporidium and Giardia in households lacking municipal sewer and water on the United States-México border. Am J Trop Med Hyg 66: 794-798.

Reinthaler FF 1989. Epidemiology of cryptosporidiosis in children in tropical countries. J Hyg Epidemiol Microbiol Immunol 33: 505-513.

Ritchie L 1948. An ether sedimentation technique for routine stool examitations. Bull US Army Med Dep 8: 326.

Tompkins VN, Miller JK 1947. Staining intestinal protozoa with ironhematoxylin-phosphotungstic acid. Am J Clin Pathol 17: 755-757.

Ungar B 1990. Cryptosporidiosis in humans. In JP Dubey, CA Speer, R Fayer (eds), Cryptosporidiosis of man and animals, CRC Press, Boca Raton, USA, p. 59-82.

Weikel CS, Johnston LI, Sousa MA, Guerrant RL 1985. Cryptosporidiosis in Northeastern Brazil: association with sporadic diarrhea. J Infect Dis 151: 963-965. 